\title{
A BRIEF HISTORY OF SIMULATION REVISITED
}

\author{
David Goldsman \\ Georgia Institute of Technology \\ H. Milton Stewart School of \\ Industrial \& Systems Engineering \\ Atlanta, GA 30332, USA
}

\author{
Richard E. Nance \\ Orca Computer, Inc. \\ 1800 Kraft Drive, Suite 111 \\ Blacksburg, VA 24060, USA
}

\author{
James R. Wilson \\ North Carolina State University \\ Edward P. Fitts Department of \\ Industrial \& Systems Engineering \\ Raleigh, NC 27695, USA
}

\begin{abstract}
In response to a request from the WSC Foundation and the WSC 2010 Program Committee, we review and slightly revise our survey of the history of simulation up to 1982, with special emphasis on some of the critical advances in the field and some of the individuals who played leading roles in those advances. Documenting the history of simulation remains a work in progress on our part, and we encourage individuals and organizations in the simulation community to bring significant historical data to our attention.
\end{abstract}

\section{INTRODUCTION}

A history of simulation can be written from many perspectives - for example, uses of simulation (analysis, training, research); types of simulation models (discrete-event, continuous, combined discretecontinuous); simulation programming languages or environments (GPSS, SIMSCRIPT, SIMULA, SLAM, Arena, AutoMod, Simio); and application domains or communities of interest (communications, manufacturing, military, transportation). Examples of the various perspectives and combinations can be readily found in the published histories; see Nance (1996), Nance and Sargent (2002), and Hollocks (2008). We offer this brief treatment from a very informal perspective; the objective is to highlight people, places, and events that have marked the development of discrete-event and Monte Carlo simulation. Within this informal perspective, and sometimes anecdotal description, lies a secondary objective: to motivate others to document their historical contributions or knowledge so that a comprehensive history can be captured for posterity in places like the Simulation Archive at North Carolina State University (NCSU 2010). The slides for the oral presentation of this article are available via ISE-NCSU (2010).

Capturing the history of a technology while the development of that technology is in progress and some contributors remain available to provide an oral history offers obvious advantages but poses not-soobvious challenges. A brief, but particularly insightful commentary, on the compilation of a contemporary history of programming languages provides valuable guidance (Tropp 1981). 


\section{THE PRECOMPUTER ERA: FROM BUFFON TO WORLD WAR II (1777-1945)}

The Monte Carlo method is generally considered to have originated with the Buffon "needle experiment" in 1777. The experiment is to "throw" needles "randomly" onto a plane with equally spaced parallel lines in order to estimate the value of $\pi$. The reader interested in the details may consult chapter 3 in Larson and Odoni (1981). Although Buffon's solution to the original needle experiment is correct, his solution to an extended version of the experiment contains an error that was corrected by Laplace in 1812. For this reason, the terminology Buffon-Laplace needle problem is frequently used. For more on this problem, visit Wolfram Research Inc. (2010).

About a century after Laplace's contribution is the perhaps surprising role played by simulation in one of the most important early developments in applied statistics. William Sealy Gosset, trained in mathematics and chemistry, became a brewer with Arthur Guiness, Son \& Co. Ltd., in 1899 at the age of 23. Guiness allowed Gosset to publish certain major statistical results, provided he used a pseudonym and no proprietary data was used. These results were published under the pseudonym "Student" beginning in 1908 with a paper formulating what is now known as Student's $t$-distribution. Because Gosset had incomplete analytical results, he used a crude form of manual simulation to verify his conjecture about the exact form of the probability density function for Student's $t$-distribution. This inaugural application of simulation to the field of industrial process control is a remarkable example of the synergy of simulationbased experimentation and analytic techniques in the discovery of the exact solution of what is arguably a classical industrial-engineering problem.

\section{THE FORMATIVE PERIOD (1945-1970)}

In the mid-1940s two major developments set the stage for the rapid growth of the field of simulation:

- The construction of the first general-purpose electronic computers such as the ENIAC (Burks and Burks 1981); and

- The work of Stanislaw Ulam, John von Neumann, Nicholas Metropolis, and others to use the Monte Carlo method on electronic computers in order to solve certain problems in neutron diffusion that arose in the design of the hydrogen bomb and that were (and still are) analytically intractable (Cooper 1988).

Ulam's fondness for card games and his attempts to find an easier way to estimate the probabilities of certain events in those card games apparently led him to the idea that a "Monte Carlo" approach to the problems of mathematical physics might be effective. An important complement to the work on the Monte Carlo method in the 1940s was the introduction of linear congruential random-number generators (LCGs) by Lehmer (1951). The increasing availability of general-purpose electronic computers in the 1950s allowed for the rapid proliferation of simulation techniques and applications in other disciplines.

Keith Douglas Tocher, a professor of operational research at the University of Southampton, developed the General Simulation Program (GSP), the first general-purpose simulator, as a tool for systematically building a simulation of an industrial plant that comprises a set of machines, each cycling through states such as busy, idle, unavailable, and failed. Obviously, the machine states and the times of the next machine actions collectively define the state of the plant (see Tocher and Owen 1960). Tocher's preeminent contributions to simulation include the three-phase method for timing executives, the first textbook in simulation, The Art of Simulation (Tocher 1963), and the wheel chart or activity-cycle diagram (ACD) in 1964. The ACD became a cornerstone of simulation teaching in the United Kingdom and the core of research in program generators during the 1970s. It is especially noteworthy that Tocher conceived and implemented an approach to combined simulation (discrete-event and continuous submodel interaction within a single model execution) well before its appearance in a US simulation language (Tocher and Splaine 1966). We are indebted to Hollocks (2008) for detailing the contributions of Tocher that led to 
the establishment of the K. D. Tocher Award by the Operational Research Society (United Kingdom) in 2008.

Geoffrey Gordon joined the Advanced Systems Development Division of IBM in 1960 as Manager of Simulation Development; and during the period 1960-1961, he introduced the General Purpose System Simulator, which was later renamed the General Purpose Simulation System (GPSS). GPSS was designed to facilitate rapid simulation modeling of complex teleprocessing systems involving, for example, urban traffic control, telephone call interception and switching, airline reservation processing, and steelmill operations. Gordon focused on a block diagram interface because he feared that programming might be too great a challenge for engineers. The ease of use and the software marketing policies of IBM at the time established GPSS as the most popular instructional simulation programming language (SPL) in the United States. An in-depth description of the history of GPSS is provided in Gordon (1981).

Based on FORTRAN, the initial version of SIMSCRIPT in 1963 was intended for users that were not computer experts and utilized a set of forms for model definition, model initialization, and report generation. The second generation SIMSCRIPT 1.5 unchained the translation from FORTRAN and served as a concept and idea generator for SIMSCRIPT II, the most ambitious language undertaking at that time. SIMSCRIPT II as published was a "layered" language, defined on five levels. Written in SIMSCRIPT II, the language was intended to have seven levels, the highest being a language writing "language" (Markowitz 1979, p. 29). Comprehensive descriptions of SIMSCRIPT are provided in Markowitz (1979) and Nance (1996).

A major contributor to the development and implementation of SIMSCRIPT II was Philip Kiviat, who had come from Cornell University to U. S. Steel in 1961 where he developed GASP (General Activity Simulation Program). Kiviat joined the RAND Corporation in 1963 and became a major driver in SIMSCRIPT II. Succeeding versions of GASP were developed by Alan Pritsker. The role of organizations (places) is emphasized by noting that Pritsker worked at RAND in the summer of 1969 on a version of GASP based on JOSS. Professor Richard Conway of Cornell also had a working relationship with RAND during this period.

Along with RAND, IBM, Cornell, and U. S. Steel, the Royal Norwegian Computing Center was a hotbed of simulation language development. Kristen Nygaard and Ole-Johan Dahl initiated work on SIMULA in 1961. With strong support from Univac, the two with capable programming staff created SIMULA I as an extension of ALGOL 60. The resulting evolution produced arguably the most influential programming language in computing history. A comprehensive description of the evolution of SIMULA is provided by Nygaard and Dahl (1981).

The 1967 forerunner of the Winter Simulation Conference (WSC) was the Conference on Applications of Simulation Using the General Purpose Simulation System, which in subsequent years was expanded to include papers on any SPL or any aspect of simulation applications. WSC is now the premier international forum for disseminating recent advances in the field of system simulation.

Concurrent with the SPL advances, R. W. Conway, B. M. Johnson, and W. L. Maxwell of Cornell University laid out the central problems of discrete-event simulation in two seminal papers, Conway, Johnson, and Maxwell (1959) and Conway (1963). These groundbreaking authors stated that simulation problems fall into two broad categories-model construction and model analysis (extracting the maximum information from the execution results).

The problems of simulation model construction include:

- Modular design of simulation programs for easy revision;

- Management of computer memory, a scarce resource during this period;

- Control of error arising from the discretization of all continuous quantities that is inherent in digital simulation;

- Design and implementation of an efficient time-advance mechanism; and

- Management of files containing the simulation entities. 


\section{Goldsman, Nance, and Wilson}

Although many of the above problems have been largely resolved, the design and implementation of an efficient time-advance procedure for handling certain types of events is still — even to this day —an active area of research and development.

The main problems in model analysis include the strategic problem of designing a simulation experiment and the following tactical problems on how to run the simulations specified in the experimental design:

- The start-up problem, i.e., determining when a simulation is in equilibrium (steady state) so that any transients caused by the simulation's initial condition have died out;

- Estimating the precision (variance) of simulation-based estimators of steady-state performance; and

- Performing precise comparisons of alternative system simulations; i.e., selection of the best of a competing set of alternative systems or system configurations.

For the start-up problem, Conway (1963) proposed the first widely used rule for truncating (deleting) simulation-generated observations that are contaminated by initialization bias. For the variance-estimation problem, Conway proposed the method of batch means, which is still widely used in practice and is the basis for a great deal of ongoing research. For the comparison problem, Conway (1963) rejected traditional ANOVA methods and proposed the use of statistical ranking-and-selection procedures, which are still commonly applied in the real world and widely studied in the high-level research literature. In brief, Conway showed remarkable insight into the problems and solution strategies that would shape the next fifty years of simulation analysis methodology.

\section{THE EXPANSION PERIOD (1970-1982)}

The "label" of the subheading marks the period as distinguished by enhancements, extensions, and additions throughout the art and science of discrete-event simulation - teaching, research, and practice. We are limited to identifying these changes; a full explanation is not possible within the space allotted.

Major changes among the SPLs, driven primarily by marketing motives, included:

- The capability for combined simulation in GASP IV, introduced by Pritsker and Hurst (1973), and in SIMSCRIPT II.5 as C-SIMSCRIPT (Delfosse 1976);

- The emergence of versions of GPSS outside the IBM domain, in particular the ascension of GPSS/H, which was developed by Henriksen (1977);

- A process interaction (transaction processing) user interface was added to SIMSCRIPT II.5 during the period 1976-1977;

- Appearance of a number of packages and processors based on the general language PL/I, notably (SIMPL/I 1972), SIML/I (MacDougall 1979), and SIMPL/I X (Metz 1981);

- Conceptual extensions of GASP to SLAM by Pritsker and Pegden (1979).

More ambitious goals for model development were driving the interactive program generator efforts in the United Kingdom. Using the ACD representation as the core structure, Clementson extended ECSL (Extended Control and Simulation Language) with the Computer Aided Programming System (CAPS); and Mathewson (1975) developed several versions of DRAFT to produce different programming language executable representations.

Concerns for more fundamental issues in model structure and representation received careful attention in the paper by Zeigler (1972) and the book that followed (Zeigler 1976). Divisions of opinion arose concerning the capabilities and limitations of system-theoretic modeling formalisms in providing a theory of simulation; yet the debate drew needed attention to breaking beyond the SPL-constrained views of the modeling task. Pursuing a path intended to join theoretical modeling issues with the program-generation 


\section{Goldsman, Nance, and Wilson}

techniques in the United Kingdom and with software engineering concepts, Nance (1981) advanced an object-oriented representational approach - the Conical Methodology (Nance 1979). The genesis of many ideas proposed in the latter paper is first described in Nance (1971).

The expansion of simulation in the 1970s is also apparent in the notable books of the decade. The importance of random number generation was established within the mainstream of computer science by the hallmark work of Knuth (1969). Textbooks appeared that broke out of a single SPL focus, e.g., Emshoff and Sisson (1970), Fishman (1973, 1978), and Law and Kelton (1982).

Other noteworthy developments include the event graphs of Schruben (1983); the development of specialty simulation products for niche markets; and the contributions of Balci and Sargent (1981) to formal verification and validation. Moreover, a great deal of the new work on random number generation, random variate generation, and output analysis appeared during the Expansion Period; and during this time, much of the theoretical work appeared that was to set the stage for the next thirty years. The classic texts of Fishman $(1973,1978)$ brought together the state-of-the-art in all of these areas, and served as the standard references for a generation of researchers. In particular, Fishman was responsible for popularizing efficient random number generation techniques (see also Knuth 1969), consolidating and enhancing random variate generation methods, and advancing and proposing various output analysis technology, including batch means, autoregressive methods, and regenerative analysis (see also Crane and Iglehart 1974a, b). The first edition of Law and Kelton (1982) brought many of these advanced methodologies to what would eventually amount to tens of thousands of practitioners.

In the area of random number generation, researchers focused on the desirable characteristics that should be displayed by a generator, and alternatives to the LCGs introduced by Lehmer (1951) were suggested, sometimes evaluated, and often limited to a specific computer arithmetic and instruction set. In the area of random number generation, researchers focused on linear congruential generators LCGs), and characteristics that good LCGs ought to have. With respect to random variate generation methods, a number of new general methodologies were developed to efficiently generate realizations from all of the usual probability distributions, as well as more-arbitrary one-dimensional and multidimensional random processes. Output analysis technology grew to encompass theoretical considerations regarding initialization bias, point and confidence interval estimation for steady-state parameters, statistical ranking-andselection methods for use in simulation, and variance reduction methods, the latter having been extensions of the seminal work of Hammersley and Handscomb (1964).

In addition to the technical innovations in simulation modeling and analysis that drove the growth of the field during the Expansion Period, there were important developments during this period in building the organizational infrastructure of the international simulation community. Noteworthy among these was the rebirth of the Winter Simulation Conference in 1976 after the 1975 WSC failed to materialize. The reestablishment of WSC with formal sponsorship by several professional societies, a Board of Directors, and by-laws governing the future operation of the conference had a decisive effect on the evolution of the field. For more on the history of WSC, see the overview on conference website (WSC 2010). Another critical development was the establishment of simulation departments in key archival journals in engineering, computer science, operations research and the management sciences, and allied fields. For more on the latter developments, see Nance and Sargent (2002).

\section{SUMMARY}

Simulation in the precomputer era is limited to innovative uses of repetitive trials to support or confirm mathematical proofs or conjectures. The importance and urgency of the nuclear diffusion investigations at Los Alamos drove the rapid application of the newly developed electronic computers to Monte Carlo techniques in the mid- and late-1940s. The principal early challenge - the discovery or invention of acceptable techniques for generating "randomness"-was confronted by some of the best mathematical minds of the period. The pioneers driving the development of more user-friendly languages during the late-1950s and early-1960s succeeded in forming the problem-solving technique of simulation (both Monte Carlo and discrete-event) as a widely recognized, powerful approach. Expansion of simulation 
along multiple dimensions (applications, uses, types) dominated the decade of the 1970s and the early 1980s. How is simulation affected by the emergence of microcomputers, increases in memory and decreases in switching time by orders of magnitude, and the ubiquity of networking technology in the future? And, what are the reactive effects of simulation? Answers to these questions form the crux of our ongoing study.

\section{ACKNOWLEDGMENTS}

We thank the WSC Foundation for sponsoring this presentation.

\section{REFERENCES}

Balci, O., and R. G. Sargent. 1981. A methodology for cost-risk analysis in the statistical validation of simulation models. Communications of the ACM 24(4):190-197.

Burks, A. W., and A. R. Burks. 1981. The ENIAC: First general-purpose electronic computer. Annals of the History of Computing 3 (4): 310-399.

Conway, R. W. 1963. Some tactical problems in digital simulation. Management Science 10(1):47-61.

Conway, R. W., B. M. Johnson, and W. L. Maxwell. 1959. Some problems of digital systems simulation. Management Science 6(1): 92-110.

Cooper, N. C., ed. 1988. From cardinals to chaos: Reflections on the life and legacy of Stanislaw Ulam. Cambridge: Cambridge University Press.

Crane, M. A., and D. L. Iglehart. 1974a. Simulating stable stochastic systems, I: General multiserver queues. Journal of the ACM 21(1):103-113.

Crane, M. A., and D. L. Iglehart. 1974b. Simulating stable stochastic systems, II: Markov chains. Journal of the ACM 21(1):114-123.

Delfosse, C.M. 1976. Continuous simulation and combined simulation in SIMSCRIPT II.5. Arlington, VA: CACI.

Emshoff, J. R. and R. L. Sisson. 1970. Design and use of computer simulation models. New York: Macmillan.

Fishman, G. S. 1973. Concepts and methods in discrete event digital simulation. New York: John Wiley $\&$ Sons.

Fishman, G. S. 1978. Principles of discrete event simulation. New York: John Wiley \& Sons.

Gordon, G. 1981. The development of the General Purpose Simulation System. In History of programming languages, ed. R. L. Wexelblatt, 403-437. New York: Academic Press.

Hammersley, J. M., and D. C. Handscomb. 1964. Monte Carlo methods. London: Chapman and Hall.

Henriksen, J. O. 1977. An improved event list algorithm. In Proceedings of the 1977 Winter Simulation Conference, ed. H. J. Highland, R. G. Sargent, and J. W. Schmidt, 547-557. Piscataway, New Jersey: Institute of Electrical and Electronics Engineers.

Hollocks, B. W. 2008. Intelligence, innovation and integrity-KD Tocher and the dawn of simulation. Journal of Simulation 2(3):128-137.

ISE-NCSU 2010. A brief history of simulation from 1777 to 1981. Available via <www.ise.ncsu.edu/jwilson/files/wsc10simhist.pdf> [accessed April 14, 2010].

Knuth, D. E. 1969. The art of computer programming, Volume 2: Seminumerical algorithms. Reading, Massachusetts: Addison-Wesley.

Larson, R.C., and A.R. Odoni. 1981. Buffon's needle experiment. In Urban operations research. New Jersey: Prentice Hall. Published online by Massachusetts Institute of Technology. Available via <web.mit.edu/urban_or_book/www/book/chapter3/3.3.1.html> [accessed April $14,2010]$.

Law, A. M., and W. D. Kelton. 1982. Simulation modeling and analysis. New York: McGraw-Hill. 
Lehmer, D. H. 1951. Mathematical methods in large-scale computing units. Annals of the Computation Laboratory of Harvard University 26:141-146.

MacDougall, M. H. 1979. The simulation language SIML/I. In Proceedings of the National Computer Conference, ed. R. E. Merwin, J. T. Zanca, and M. Smith, 39-44, Montvale, New Jersey: AFIPS Press.

Markowitz, H. M. 1979. SIMSCRIPT: Past, present, and some thoughts about the future. In Current issues in computer simulation, ed. N. R. Adam and A. Dogramaci, 27-60. New York: Academic Press.

Matthewson, S. C. 1975. Interactive simulation program generators. In Proceedings of the European computing conference on interactive systems, 423-429, Uxbridge, United Kingdom: Online Conferences, Ltd.

Metz, W. C. 1981. Discrete event simulation using PL/I based general and special purpose simulation languages. In Proceedings of the 1981 Winter Simulation Conference, ed. T I. Ören, C. M. Delfosse, and C. M. Shub, 45-52. Piscataway, New Jersey: Institute of Electrical and Electronics Engineers.

Nance, R. E. 1971. On time flow mechanisms for discrete systems simulation. Management Science 18(1):59-73.

Nance, R. E. 1979. Model representation issues in discrete event simulation: Prospects for developing documentation standards. In Current issues in computer simulation, ed. N.R. Adam and A. Dogramaci, 83-97. New York: Academic Press.

Nance, R. E. 1981. The state and time relationships in simulation modeling. Communications of the ACM 24(4):173-179.

Nance, R. E. 1996. A history of discrete event simulation programming languages. In History of programming languages II, ed. T. J. Bergin and R. J. Gibson, 369-427. New York: ACM Press; Reading, Massachusetts: Addison-Wesley.

Nance, R. E., and R. G. Sargent. 2002. Perspectives on the evolution of simulation. Operations Research 50(1):161-172.

NCSU 2010. Simulation archive. North Carolina State University Libraries. Available via <tinyurl.com/simarchive> [accessed April 14, 2010].

Nygaard, K., and O.-J. Dahl. 1981. The development of the SIMULA languages. In History of programming languages, ed. R. L. Wexelblatt, 439-493. New York: Academic Press.

Pritsker, A. A. B., and N. R. Hurst. 1973. GASP IV: a combined continuous-discrete FORTRAN-based simulation language. SIMULATION 21(3):65-70.

Pritsker, A. A. B., and C. D. Pegden. 1979. Introduction to simulation and SLAM. New York: Halsted Press, John Wiley \& Sons.

Schruben, L. W. 1983. Simulation modeling with event graphs. Communications of the ACM 26(11):957-963.

SIMPL/I. 1972. Simulation language based on PL/I: program reference manual. Publication number SH19-5060-0. IBM (June).

Tocher, K. D. 1963. The art of simulation. London: The English Universities Press Ltd.

Tocher, K. D., and D. G. Owen. 1960. The automatic programming of simulations. In Proceedings of the Second International Conference on Operational Research, ed. J. Banbury and J. Maitland, 50-68. London: The English Universities Press Ltd.

Tocher, K. D., and M. Splaine. 1966. Computer control of the Bessemer process. Journal of the Iron and Steel Institute 204 (February): 81-86.

Tropp, H. 1981. On doing contemporary history. In History of programming languages, ed. R. L. Wexelblatt, xxi-xxiii. New York: Academic Press.

Wolfram Research Inc. 2010. Buffon-Laplace needle problem. Available via < http: //mathworld.wolfram.com/Buffon-LaplaceNeedleProblem.html> [accessed April 14, 2010].

WSC 2010. The Winter Simulation Conference: the premier forum on simulation practice and theory. Available via: <www.wintersim.org/article.htm> [accessed April 14, 2010]. 
Zeigler, B. P. 1972. Towards a formal theory of modeling and simulation Structure preserving morphisms. Journal of the ACM 19(4):742-764.

Zeigler, B. P. 1976. Theory of modeling and simulation. New York: John Wiley \& Sons.

\section{AUTHOR BIOGRAPHIES}

DAVID GOLDSMAN is a Professor in the H. Milton Stewart School of Industrial and Systems Engineering at the Georgia Institute of Technology. His research interests include simulation output analysis, ranking and selection, and healthcare simulation. He is an active participant in the Winter Simulation Conference, having been Program Chair in 1995, and having served on the WSC Board of Directors during the period 2002-2009. His e-mail address is <smanegatech.edu>, and his Web page is $<$ www.isye.gatech.edu/ sman>.

RICHARD E. NANCE is an Emeritus Professor of Computer Science at Virginia Tech and Chief Scientist, Orca Computer, Inc. He received B.S. and M.S. degrees from North Carolina State University in 1962 and 1966, and the Ph.D. degree from Purdue University in 1968. He has served on the faculties of Southern Methodist University and Virginia Tech, where he was Department Head of Computer Science, 1973-1979. Dr. Nance held research appointments at the Naval Surface Weapons Center (1979-1980) and at the Imperial College of Science and Technology (UK). Within ACM, he has chaired two special interest groups: Information Retrieval (SIGIR), 1970-1971, and Simulation (SIGSIM), 19831985. He is the author of over 150 papers on discrete event simulation, performance modeling and evaluation, computer networks, and software engineering. Dr. Nance has held several editorial positions and was the founding Editor-in-Chief of the ACM Transactions on Modeling and Computer Simulation, 1990-1995. He served as Program Chair for the 1990 Winter Simulation Conference. Dr. Nance has received several awards for his editorial and professional contributions, most recently the Lifetime Professional Achievement Award from the INFORMS Simulation Society. He was named an ACM Fellow (1996) and an INFORMS Fellow (2008). In 2006 he was designated by the faculty as a Distinguished Alumnus of the Edward P. Fitts Department of Industrial and Systems Engineering, North Carolina State University. He is a member of Sigma Xi, Alpha Pi Mu, Upsilon Pi Epsilon, ACM, and INFORMS. His email address is $<$ nanceevt.edu>.

JAMES R. WILSON is a professor in the Edward P. Fitts Department of Industrial and Systems Engineering at North Carolina State University. Dr. Wilson's current research interests are focused on probabilistic and statistical issues in the design and analysis of simulation experiments. Dr. Wilson has held the following editorial positions: departmental editor of Management Science (1988-1996); area editor of ACM Transactions on Modeling and Computer Simulation (1997-2002); guest editor of a special issue of IIE Transactions honoring Alan Pritsker (1999-2001); and Editor-in-Chief of ACM Transactions on Modeling and Computer Simulation (2004-2010). He served The Institute of Management Sciences College on Simulation as secretary-treasurer (1984-1986); vice president (1986-1988); and president (1988-1990). As a participant in the Winter Simulation Conference (WSC), he served as proceedings editor (1986); associate program chair (1991); and program chair (1992). As a member of the WSC Board of Directors corepresenting the INFORMS Simulation Society during the period 1997-2004, he has served as secretary (2001); vice chair (2002); and chair (2003). As a trustee of the WSC Foundation during the period 2006-2009, he served as secretary (2006), vice-president (2007), and president (2008). He is a member of ACM, ASA, and SCS; and he is a Fellow of IIE and INFORMS. His e-mail address is <jwilson@ncsu. edu $>$, and his Web page is <www.ise. ncsu. edu/jwilson>. 